\title{
THE CHEMICAL ESTIMATION OF ACYL GLUCURONIDES AND ITS APPLICATION TO STUDIES ON THE METABOLISM OF BENZOATE AND SALICYLATE IN MAN
}

\author{
BY DAVID SCHACHTER 1 \\ (From the Department of Pharmacology-Biochemistry, School of Aviation Medicine, USAF, \\ Randolph Air Force Base, Tex.)
}

(Submitted for publication September 17, 1956; accepted October 18, 1956)

Structurally, glucuronides are the condensation products of hydroxyl-bearing compounds with the first, hemiacetal carbon of D-glucuronic acid. Two groups have been described (1). Alcohols and phenols form ethereal glucuronides, which are resistant to hydrolysis by mild alkali and do not reduce alkaline copper reagents. Carboxylic acids form ester glucuronides, which are easily split by mild alkali to liberate free glucuronic acid, a reducing agent. The term acyl glucuronide is introduced here for members of the latter group to denote clearly conjugation via the carboxyl group.

Another chemical reaction characteristic of the acyl glucuronides is described in this report. At room temperature and neutral $\mathrm{pH}$, the acyl group can be transferred to hydroxylamine to form characteristic hydroxamic acids (Reaction I). acids in man. Since urinary glucuronides have been found following the ingestion of benzoate, salicylate, and probenecid $(1,3)$, observations were made on the metabolism of these clinically important drugs.

\section{METHODS AND MATERIALS}

Drug experiments. The subject was a healthy 28year-old white male, weighing 60 kilos. His diet was not rigidly controlled, but remained fairly uniform throughout the period of investigation; all experiments were begun in the fasting state. At least 2 weeks elapsed between successive doses of drug. On the morning of an experiment, a control urine was collected over a period of several hours, and the appropriate drug was ingested as a solution of its sodium salt. Subsequently, timed voided urine samples were tested immediately for acyl glucuronides and stored at $5^{\circ} \mathrm{C}$ until completion of the remaining estimations. When necessary, the excretory

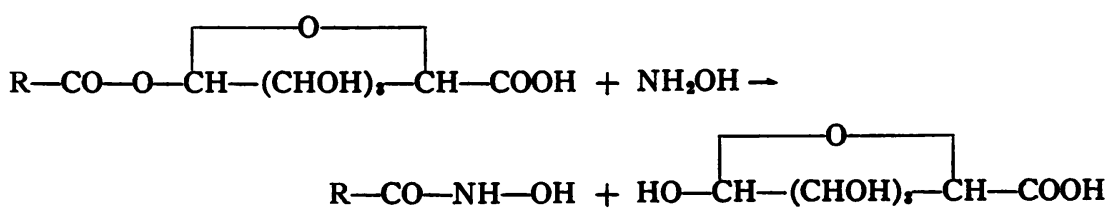

On addition of acid ferric chloride solution, hydroxamic acids yield colored products which can be measured spectrophotometrically (2). Thus, conversion to the stable hydroxamates provides a sensitive, chemical method for estimating the relatively unstable acyl glucuronides. The derivatives are easily extracted into organic solvents, and can be identified by chromatographic and other techniques. Non-acyl glucuronides do not form hydroxamic acids.

The methods reported here have permitted more extensive studies on the metabolic fate of aromatic

1 Present address : Department of Medicine, College of Physicians and Surgeons, New York City, N. Y. rates of urinary drug metabolites were corrected for pre-ingestion, endogenous rates.

Estimation of acyl glucuronides. These compounds are estimated by conversion to their hydroxamates, using modifications of the procedure of Lipmann and Tuttle (2). The $\mathrm{pH}$ of the neutralized hydroxylamine reagent is critical and should be $7.0 \pm 0.2$. Stock solutions of $\mathrm{NaOH}$ (14 per cent) and hydroxylamine hydrochloride (28 per cent) are titrated against each other with a Beckman glass electrode $\mathrm{pH}$ meter to determine the exact proportions required. Urine samples containing 0.5 to $2.0 \mu$ moles of acyl glucuronide are incubated with 0.5 $\mathrm{ml}$. of freshly prepared neutral hydroxylamine for 2 hours at room temperature before color development and comparison with authentic hydroxamate standards. Figure 1 demonstrates the complete conversion of benzoyl glucuronide to benzoyl hydroxamate under these conditions. 


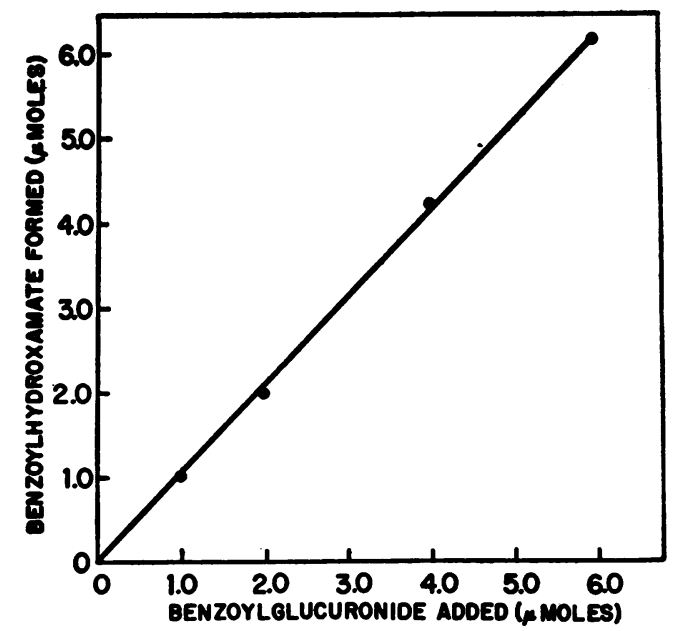

Fig. 1. Quantttative Conversion of Benzoyl GluCURonide to Benzoyl Hydroxamate

The indicated amounts of crystalline benzoyl glucuronide in $0.5 \mathrm{ml}$. water were mixed with $0.5 \mathrm{ml}$. neutral hydroxylamine and incubated 2 hours at room temperature. The volume was adjusted to $2.0 \mathrm{ml}$. with water, and $0.5 \mathrm{ml}$. of $3 \mathrm{~N} \mathrm{HCl}$ followed by $0.5 \mathrm{ml}$. of 5 per cent $\mathrm{FeCl}_{3} \cdot 6 \mathrm{H}_{2} \mathrm{O}$ in $0.1 \mathrm{~N} \mathrm{HCl}$ added. The optical density at $540 \mathrm{~m} \mu$ was compared with that of a benzoyl hydroxamate standard.

To estimate salicyl acyl glucuronide (SAG) in urine by this procedure, $6 \mathrm{~N} \mathrm{HCl}$ is substituted for $3 \mathrm{~N} \mathrm{HCl}$ to minimize the formation of purple products arising from salicylate and salicylurate. Further, a correction is made in each estimation by subtracting the optical density at $540 \mathrm{~m} \mu$ of a similarly treated, hydroxylamine-free control. ${ }^{2}$

The specificity of hydroxamate formation was studied with a series of 9 glucuronides, using $2.0 \mu$ moles of each in the assay. (The conditions are described in the legend to Figure 1). Only benzoyl- and o-methoxybenzoyl glucuronides yielded such products, and no reaction was observed with the glucuronides of salicylamide, $\mathrm{N}$-acetyl salicylohydrazine, 3-hydroxycoumarin, pregnandiol, phenolphthalein, menthol, and borneol.

Identification of urinary acyl glucuronides. Urinary hydroxamate-forming materials appear after the administration of benzoate and salicylate. The following evidence identifies these as benzoyl- and salicyl acyl glucuro-

2 A satisfactory method of eliminating blank values due to salicylate and salicylurate is to extract the reaction mixture after formation of salicyl hydroxamate with 4 volumes of ether at neutral $\mathrm{pH}$. Salicylate and salicylurate remain behind, while over 90 per cent of the hydroxamate is extracted. An aliquot of the ether is evaporated and color developed with $\mathrm{HCl}$ and ferric chloride. Values for acyl glucuronide in salicyl urine were identical, when estimated by both this procedure and that described in the text. nides (SAG), respectively. These compounds are completely hydrolyzed by $0.1 \mathrm{~N} \mathrm{NaOH}$ in 10 minutes at room temperature, and 84 per cent hydrolyzed by incubation with bacterial $\beta$-glucuronidase (250 units per ml.) for 60 minutes at $38^{\circ} \mathrm{C}$. A single hydroxamate spot was detected for each compound by paper chromatography of urinary aliquots, using Whatman No. 1 paper and the ascending technique, with water-saturated n-butanol : glacial acetic acid $(80: 20, v / v)$ as the solvent system. These spots reduce aniline phthalate (4), and give a positive carbazole reaction for hexuronic acid (5) after elution into water. The benzoate metabolite moves at a rate ( $R f 0.67$ ) similar to that of crystalline benzoyl glucuronide. The salicylate conjugate ( $\operatorname{Rf} 0.72$ ) liberates free salicylate on hydrolysis in $6 \mathrm{~N} \mathrm{HCl}$ at $100^{\circ} \mathrm{C}$ for 1 hour.

The hydroxamate derivatives of these urinary metabolites were extracted at neutral $\mathrm{pH}$ into ether and chromatographed on paper as described above, with watersaturated n-butanol as the developing solvent. Movement of the benzoyl derivative (Rf 0.79 ) corresponded to that of an authentic sample of benzoyl hydroxamate, and that of the salicyl compound ( $\mathrm{Rf} 0.85$ ) to crystalline salicyl hydroxamate.

That the urinary SAG is a monoglucuronide has been established in the following manner: its hydroxamate is completely extractable into ether, while that of the diglucuronide would be ether-insoluble. In addition, the hydroxamate is chromatographically homogeneous and identical in behavior with synthetic salicyl hydroxamate.

Estimation of urinary salicyl metabolites. In addition to SAG, salicyl phenolic glucuronide (SPG), salicylurate, and total salicyl were estimated.

SPG accounts for the difference between the quantity of SAG and the total salicyl glucuronide excreted. The latter is estimated by the salicylate liberated by bacterial $\boldsymbol{\beta}$-glucuronidase. An aliquot of urine, adjusted to $\mathrm{pH} 2$, is extracted twice with an equal volume of ether to remove salicylate and salicylurate, and readjusted to $\mathrm{pH}$ 6.0. Samples are withheld for initial salicylate (6) and SAG determinations. Five hundred units of $\beta$-glucuronidase are added to each $\mathrm{ml}$. of extracted urine, the mixture is incubated at $38^{\circ} \mathrm{C}$ for 8 hours, an identical amount of enzyme again added and the incubation repeated. ${ }^{3}$ Finally, 10 per cent perchloric acid filtrates are prepared and the free salicylate concentrations again determined.

$$
\text { SPG }=\text { final salicylate }- \text { initial salicylate }- \text { SAG }
$$

Salicylurate is estimated by a paper chromatographic technique. Suitable volumes of urine are quantitatively applied in duplicate to Whatman No. 1 paper for ascend-

\footnotetext{
${ }^{8}$ Enzyme-treated urine was further hydrolyzed in 6 $\mathrm{N} \mathrm{HCl}$ at $100^{\circ} \mathrm{C}$ for 3 hours, and free salicylate again estimated. The results indicated that enzymatic hydrolysis was at least 80 per cent complete under the conditions described in the text. Enzymatic hydrolysis is preferable to acid hydrolysis since specificity for glucuronides is obtained.
} 
ing chromatography, with n-butanol: ethanol (40:11, $\mathrm{v} / \mathrm{v}$ ) saturated with an ammonium carbonate buffer (7) as the solvent system. The dried paper chromatograms are viewed with an ultra-violet lamp, and the fluorescent salicylurate areas ( $\operatorname{Rf} 0.31$ ) outlined and eluted into water. (The salicylate fluorescent area corresponds to Rf 0.66.) To $2.8 \mathrm{ml}$. of eluate, containing about $0.5 \mu$ mole salicylurate, $0.2 \mathrm{ml}$. of $0.1 \mathrm{M}$ ferric chloride in $0.07 \mathrm{~N}$ $\mathrm{HCl}$ is added. The optical density of the purple products is measured at $540 \mathrm{~m} \mu$ in the Beckman model B spectrophotometer. Recoveries of known quantities of salicylurate, chromatographed simultaneously, have ranged from 90.0 to 102.0 per cent.

The procedure of Lester, Lolli, and Greenberg was followed in estimating total urinary salicyl.4

Corrected total salicyl $=$ observed total salicyl + salicylurate $\times 0.676 \times 0.225+$ salicylurate $\times 0.676 \times$

$0.775-$ salicylurate $\times 0.676 \times 0.775 \times 0.84$

Corrected total salicyl $=$ observed total salicyl + salicylurate $\times 0.236$. The salicylurate concentration is estimated by the chromatographic method described in the text.

Other methods. Chemical estimations were employed for hippurate (9), hexuronic acid (5), and probenecid (3). Probenecid conjugates were hydrolyzed by refluxing in $4.0 \mathrm{~N} \mathrm{H}_{2} \mathrm{SO}_{4}$ for 60 minutes. Optical density measurements were made in the Beckman model $B$ spectrophotometer.

Materials. The following compounds were prepared according to published methods and recrystallized from hot water: benzoyl glucuronide (10), m.p. 181-2 $2^{\circ}$ (decomp.) (Pryde and Williams: $\left.183^{\circ}[11]\right)$; salicyluric acid (12), m.p. $166^{\circ}$ (Quick: $167^{\circ}$ [12]); salicyl hydroxamic acid (13), m.p. $168^{\circ}$ (Jeanrenaud: $168^{\circ}[13]$ ). A reference standard solution of benzoyl hydroxamate was prepared by reaction of neutral hydroxylamine with recrystallized benzoic anhydride (14). Crystalline salicylamide glucuronide $\left(174^{\circ}\right)$, o-methoxybenzoyl glucuronide $\left(123-4^{\circ}\right)$, and $\mathrm{N}$-acetyl salicylohydrazine glucuronide (208-10 ${ }^{\circ}$ ) were gifts from Doctor R. T. Williams to Captain R. M. Dowben; 3-hydroxycoumarin glucuronide $\left(207-8^{\circ}\right)$ was a gift from Captain R. M. Dowben; menthol-, borneol-, pregnandiol-, and phenolphthalein glucuronides were purchased from the Sigma Chemical Company, as was the bacterial $\beta$-glucuronidase.

4 In this procedure aliquots of salicyl urine are hydrolyzed to liberate salicylic acid, which is extracted into ether and estimated by reaction with ferric chloride. The "total salicyl" concentration so measured requires complete hydrolysis of all salicyl conjugates. However, 67.6 per cent of the glycine conjugate remains unhydrolyzed, as determined by the liberation of glycine (8) in similarly treated salicyluric acid solutions. Hence it is necessary to correct the observed total salicyl concentration for: 1) incomplete ether extraction of salicylurate ( 77.5 per cent as compared to 100 per cent for salicylate), and 2) relative intensity of the colored products formed with ferric chloride ( 84.0 per cent for salicylurate as compared to salicylate).

\section{RESULTS}

\section{Ingestion of benzoate}

In individual experiments, the subject was fed $6.9,13.9,34.7$, and 69.3 millimoles of sodium benzoate. ${ }^{5}$ Complete elimination of the drug as urinary hippurate and benzoyl glucuronide ensued in each instance, with final recoveries of 98 to 104 per cent. The relative amounts of benzoate conjugated with glycine and with glucuronic acid varied with the dosage, as shown in Figure 2. The glucuronide moiety increased progressively from 0.4 per cent ( 0.03 millimoles) to 3.0 per cent (2.08 millimoles). Hippurate accounted for the bulk of conjugated benzoate throughout this dose range.

The cumulative urinary recovery of each metabolite is plotted in Figure 3 for a representative experiment. The recoveries of acyl glucuronide and hippurate ran a parallel course, a characteristic observed at all the dosage levels examined. Complete excretion of benzoate required 3 to 4 hours after the two smaller doses, and 10 to 14 hours after the larger amounts.

As indicated in Table $I$, the maximal urinary excretory rate ( $\mu$ moles per minute) achieved in a given experiment by either metabolite depended on the dose of benzoate. Limiting values for hip-

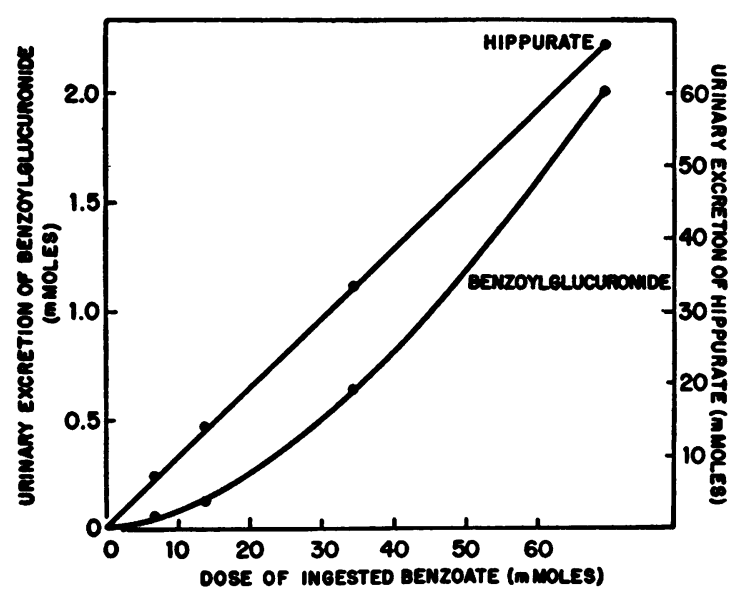

Fig. 2. Quantities of Urinary Hippurate and Benzoyl Glucuronide Recovered after Various Doses OF BENZOATE

The right- and left-hand vertical scales refer to hippurate and benzoyl glucuronide, respectively.

\footnotetext{
5 Corresponding to $1.0,2.0,5.0$, and 10.0 grams.
} 


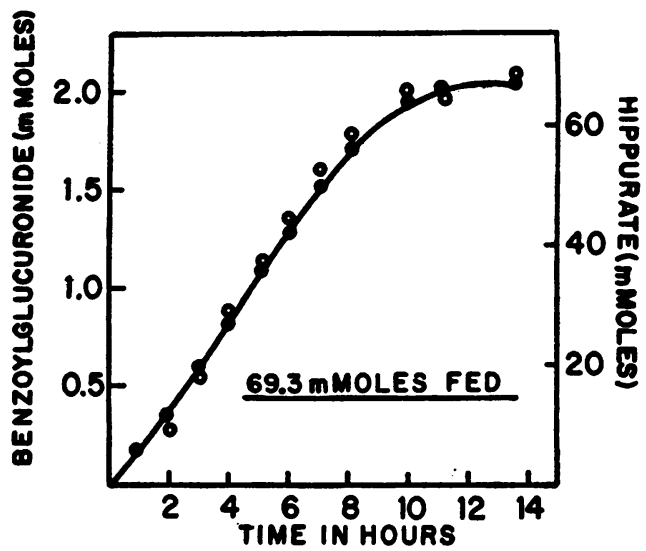

Fig. 3. Cumulative Urinary Recoveries of Hippurate (一-O-) and Benzoyl Glucuronide (O)

purate excretion were approached at a dose of 13.9 millimoles. Quick (15) has demonstrated that limitations in the availability of glycine may account for this, and the peak rate attained in these experiments ( $130.5 \mu$ moles per minute) is within his range for maximal rates of glycine mobilization in man (122 to $155 \mu$ moles per minute). By contrast, the maximal excretory rate of benzoyl glucuronide was approximately proportional to the benzoate dose throughout the range studied. It is significant that the glucuronide was

TABLE I

Maximal rates of hippurate and bensoyl glucuronide excretion following various doses of benzoate

\begin{tabular}{|c|c|c|c|}
\hline \multicolumn{2}{|c|}{$\begin{array}{l}\text { Dose of } \\
\text { sodium benzoate }\end{array}$} & \multicolumn{2}{|c|}{$\begin{array}{l}\text { Maximal urinary excretory rate } \\
\text { (umoles per min.) }\end{array}$} \\
\hline (grams) & (millimoles) & Hippurate & $\begin{array}{l}\text { Benzoyl } \\
\text { glucuronide }\end{array}$ \\
\hline $\begin{array}{r}1.0 \\
2.0 \\
5.0 \\
10.0\end{array}$ & $\begin{array}{r}6.9 \\
13.9 \\
34.7 \\
69.3\end{array}$ & $\begin{array}{r}54.8 \\
108.2 \\
111.3 \\
130.5\end{array}$ & $\begin{array}{l}0.4 \\
1.0 \\
2.6 \\
5.5\end{array}$ \\
\hline
\end{tabular}

detected at a dosage level (6.9 millimoles) far below that required for maximal hippurate excretion. These observations fail to support the supposition (15) that the glucuronide synthesis is a reserve detoxication mechanism, operating only when the glycine supply is exceeded. Further pertinent evidence is obtained from the data in Figure 3. After the seventh hour in this experiment, the excretion of hippurate was well below its maximal rate, yet significant benzoyl glucuronide excretion persisted.

\section{Ingestion of salicylate}

Four experiments were performed, the subject ingesting 7.5, 15.0, 22.5, and 30.0 millimoles of sodium salicylate. ${ }^{6}$ The relative quantities of urinary salicyl metabolites excreted after these doses are listed in Table II. With doses of 15.0 to 30.0 millimoles about 50 per cent of the amount fed was recovered as urinary salicyl in 24 hours (and 85 per cent at the end of 48 hours). Salicylurate made up 60 per cent of this, and the glucuronides 30 per cent, values which agree closely with previous observations $(12,16)$. SAG and SPG were present in about equal amounts. Cumulative urinary recoveries of the salicyl metabolites, in a representative experiment, are depicted in Figure 4. Whereas total salicyl, salicylurate, and SAG ran a course parallel to each other with time, the recovery of SPG was relatively lower in the early hours and higher thereafter. The maximal rates of excretion ( $\mu$ moles per minute) of the urinary products varied with the doses, as shown in Table II ; limiting values for these rates were not achieved in this range.

Characteristic differences in the excretory patterns of SAG and SPG were observed in all the

${ }^{6}$ Corresponding to $1.0,2.1,3.1$, and 4.2 grams.

TABLE II

Urinary metabolites of salicylate following various oral doses

\begin{tabular}{|c|c|c|c|c|c|c|c|c|}
\hline \multirow[b]{2}{*}{$\begin{array}{l}\text { Dose } \\
\text { (millimoles) }\end{array}$} & \multirow{2}{*}{$\begin{array}{l}\text { Urinary } \\
\text { salicyl } \\
\text { recovered } \\
\text { in } 24 \text { hours, } \\
\text { per cent } \\
\text { of dose }\end{array}$} & \multicolumn{3}{|c|}{$\begin{array}{l}\text { Urinary metabolites recovered } \\
\text { in } 24 \text { hours, per cent of total } \\
\text { urinary salicyl }\end{array}$} & \multicolumn{4}{|c|}{$\begin{array}{c}\text { Maximal rates of urinary excretion } \\
\text { ( } \mu \text { moles per min.) }\end{array}$} \\
\hline & & $\begin{array}{l}\text { Salicyl- } \\
\text { urate }\end{array}$ & SAG & SPG & $\begin{array}{l}\text { Total } \\
\text { salicyl }\end{array}$ & $\begin{array}{l}\text { Salicyl- } \\
\text { urate }\end{array}$ & SAG & SPG \\
\hline $\begin{array}{r}7.5 \\
15.0 \\
22.5 \\
30.0\end{array}$ & $\begin{array}{l}78.6 \\
54.5 \\
49.4 \\
50.8\end{array}$ & $\begin{array}{l}64.5 \\
62.8 \\
74.0 \\
59.6\end{array}$ & $\begin{array}{l}13.1 \\
14.8 \\
14.3 \\
16.4\end{array}$ & $\begin{array}{l}12.7 \\
21.0 \\
15.1 \\
12.1\end{array}$ & $\begin{array}{r}4.5 \\
5.6 \\
8.0 \\
11.1\end{array}$ & $\begin{array}{l}3.0 \\
4.1 \\
6.0 \\
6.8\end{array}$ & $\begin{array}{l}0.8 \\
1.0 \\
1.5 \\
1.9\end{array}$ & $\begin{array}{l}0.6 \\
1.4 \\
1.5 \\
1.7\end{array}$ \\
\hline
\end{tabular}




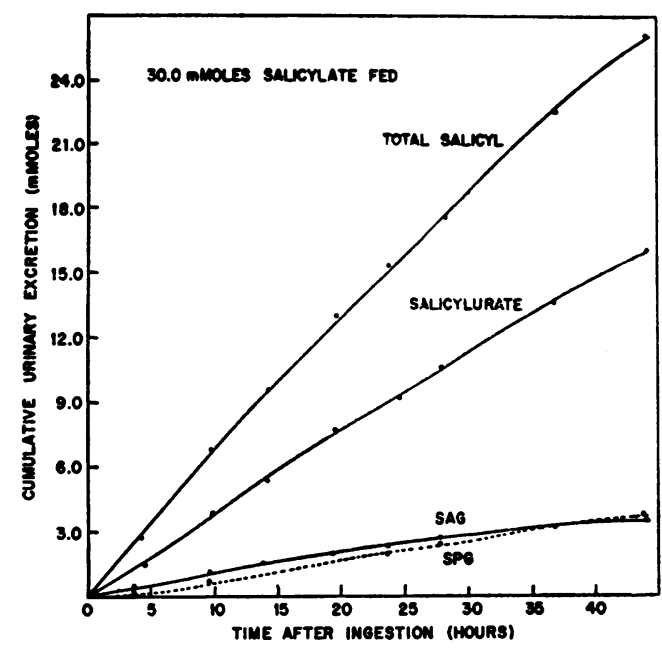

Fig. 4. Cumulative Urinary Recoveries of Salicyi. Metabolites

experiments. These are illustrated in Figure 5. The peak SAG excretory rates were observed within 5 to 10 hours after ingestion, with a rapid fall thereafter. By contrast, the SPG peak was obtained after 20 to 30 hours, and the subsequent fall-off was more gradual.

\section{Ingestion of probenecid}

Seven and one-half millimoles (2.1 grams) of this drug (sodium p-(dipropylsulfamyl) benzoate) were administered to the subject. At the end of

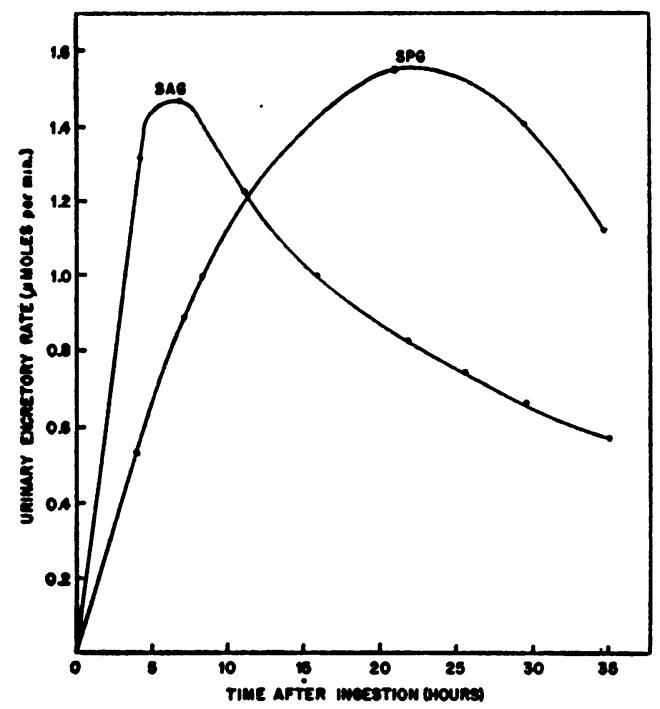

Fig. 5. Rates of Urinary Excretion of SAG and SPG after Ingestion of Salicylate the first, second, third, and fourth days, the cumulative urinary recoveries were $35.1,59.1,73.8$, and 79.1 per cent. Consistently, 80 per cent appeared as the acyl glucuronide. The excretion of total hexuronic acid, estimated by the carbazole method, was equivalent to that of acyl glucuronide. By contrast, the urinary hexuronic acid concentration following benzoate was over three times that of benzoyl glucuronide, and after salicylate twice as much as that of the combined glucuronides. It thus seems likely that probenecid glucuronide is much less susceptible to hydrolysis in the body than the glucuronides of benzoate and salicylate.

\section{DISCUSSION}

Previous investigators have described the transfer to hydroxylamine of acyl groups linked to acids as anhydrides (2), or to alcohols as esters (17). It is of interest, therefore, that the acyl glucuronides, which constitute an intermediate category with acyl groups linked to a hemiacetalbearing carbon, also form hydroxamates. This provides a sensitive method for their chemical estimation, and further characterizes them as a unique group within the class of glucuronides.

Conversion to the stable hydroxamates offers the advantage of a trapping mechanism for the readily hydrolyzed acyl glucuronides. These hydroxamates are readily extracted, purified, and subsequently identified. As a differential reaction, the hydroxamate method allows separate estimation of acyl and non-acyl glucuronides in mixtures of both. These several advantages made possible the observations described in this report.

Excretion of benzoyl glucuronide could be detected following the administration of as little as 6.9 millimoles of benzoate, although several times this amount has been required in the past (15). Thus it could be demonstrated that the glucuronide synthesis occurs independently, whether or not glycine conjugation is maximal. Only a minimal estimate of the actual rate of benzoyl glucuronide synthesis is obtained from the urinary recovery, as noted by Quick (15). The extent to which this conjugate may be broken down in the body is suggested by the three-fold excess of urinary hexuronic acid relative to benzoyl glucuronide. Therefore, it seems inappropriate to designate benzoyl glucuronide formation as merely a spare detoxication mechanism. 
Following the oral administration of salicylate in this subject, three metabolites-salicylurate, SAG, and SPG-accounted for 90 per cent or more of the total urinary salicyl recovered. Other authors $(6,16)$ have reported the excretion of 20 to 25 per cent unconjugated salicylate under roughly comparable conditions, a difference possibly due to the breakdown of labile SAG, particularly in alkaline urines collected over prolonged periods. Kapp and Coburn (16) noted the urinary excretion of both acid- and alkaline-labile salicyl glucuronides, ${ }^{7}$ and estimated their quantities. These authors suggested a diglucuronide structure for these conjugates, a possibility which the present results do not support. Of special interest was their subject W. J., who excreted equal amounts of the two glucuronides in the first 12 hours after intravenous salicylate, but almost twice as much acid-labile as alkaline-labile material in the succeeding 12 hours. These results clearly reflect the characteristic differences in the urinary excretory patterns of SAG and SPG described in the present studies.

\section{SUMMARY}

1. Acyl glucuronides react with hydroxylamine to form hydroxamic acids. This reaction may be applied to their estimation, purification, and identification.

2. Benzoate, salicylate, and probenecid elicited the urinary excretion of their respective acyl glucuronides when ingested orally by a normal subject.

3. Doses of sodium benzoate were quantitatively recovered as urinary hippurate and benzoyl glucuronide.

4. At least 90 per cent of various doses of salicylate was recovered as urinary salicylurate, salicyl acyl glucuronide, and salicyl phenolic glucuronide. Characteristic differences in the urinary excretory patterns of salicyl acyl glucuronide and salicyl phenolic glucuronide were described.

\section{REFERENCES}

1. Williams, R. T., Detoxication Mechanisms; The Metabolism of Drugs and Allied Organic Compounds. New York, John Wiley and Sons, Inc., 1947.

${ }^{7}$ SAG is alkaline-labile, and SPG acid-labile.
2. Lipmann, F., and Tuttle, L. C., A specific micromethod for the determination of acyl phosphates. J. Biol. Chem., 1945, 159, 21.

3. Beyer, K. H., Russo, H. F., Tillson, E. K., Miller, A. K., Verwey, W. F., and Gass, S. R., 'Benemid', p-(di-n-propylsulfamyl)-benzoic acid: its renal affinity and its elimination. Am. J. Physiol., 1951, $166,625$.

4. Cramer, F., Paper Chromatography, 2nd ed., London, Macmillan and Co. Ltd., New York, St. Martin's Press, 1954.

5. Dische, Z., A new specific color reaction of hexuronic acids. J. Biol. Chem., 1947, 167, 189.

6. Lester, D., Lolli, G., and Greenberg, L. A., The fate of acetylsalicylic acid. J. Pharmacol. \& Exper. Therap., 1946, 87, 329.

7. Fewster, M. E., and Hall, D. A., Application of buffered solvent system to the detection of aromatic acids by paper partition chromatography. Nature, 1951, 168, 78.

8. Alexander, B., Landwehr, G., and Seligman, A. M., A specific micro-method for the colorimetric determination of glycine in blood and urine. J. Biol. Chem., 1945, 160, 51.

9. Chantrenne, $H$. ., The requirement for coenzyme $A$ in the enzymatic synthesis of hippuric acid. J. Biol. Chem., 1951, 189, 227.

10. Quick, A. J., The preparation and study of $\beta$-d-glycuronic acid monobenzoate (benzoyl glycuronic acid). J. Biol. Chem., 1926, 69, 549.

11. Pryde, J., and Williams, R. T., The biochemistry and physiology of glucuronic acid. III. The structure of benzoylglucuronic acid. Biochem. J., 1933, 27, 1210.

12. Quick, A. J., The relationship between chemical structure and physiological response. IV. Conjugation of salicylic acid with glycine and its action on uric acid excretion. J. Biol. Chem., 1933, $101,475$.

13. Jeanrenaud, A., Ueber die Einwirkung des Hydroxylamins auf säure-äther. Ber. d. deutsch. chem. Gesellsch., 1889, 22, 1270.

14. Schachter, D., and Taggart, J. V., Benzoyl coenzyme A and hippurate synthesis. J. Biol. Chem., 1953, 203, 925.

15. Quick, A. J., The conjugation of benzoic acid in man. J. Biol. Chem., 1931, 92, 65.

16. Kapp, E. M., and Coburn, A. F., Urinary metabolites of sodium salicylate. J. Biol. Chem., 1942, 145, 549.

17. Hestrin, S., The reaction of acetylcholine and other carboxylic acid derivatives with hydroxylamine, and its analytical application. J. Biol. Chem., 1949, $180,249$. 